\title{
EL DISCURSO ÉTICO DE AMPARO POCH Y GASCÓN: ANARCOFEMINISMO, DIVULGACIÓN CIENTÍFICA Y PACIFISMO
}

\author{
ETHICAL SPEECH BY AMPARO POCH Y GASCÓN: ANARCHO-FEMINISM, \\ SCIENTIFIC OUTREACH AND PACIFISM
}

Anna Mellado García

I.E.S Poeta Julián Andúgar (Santomera-Murcia)

\section{RESUMEN:}

Destacada figura de la historia del feminismo español, la doctora Amparo Poch y Gascón fue una activista libertaria responsable de organizaciones humanitarias, militante sindical y Consejera delegada del gobierno republicano que procuró la divulgación científica, proporcionó las claves para la emancipación de las mujeres y difundió el mensaje pacifista en un contexto de guerra.

\section{PALABRAS ClAVES:}

Anarcofeminismo, Pacifismo, Divulgación científica, República.

\section{ABSTRACT:}

A leading figure in the history of Spanish feminism, the doctor Amparo Poch y Gascón was a libertarian activist responsible for humanitarian organizations, union militant, and counsellor deputy in the Republican Government, who sought the scientific divulgation, provided the keys for the women's emancipation and transmitted the pacifist message in a war context.

\section{KEY WORD:}

Anarcho-Feminism, Pacifism, Scientific divulgation, Republic. 
La amnesia histórica colectiva de España procurada por el régimen franquista y, por otra parte, la versión deformada de historiadores afectos al franquismo sobre los movimientos sociales y políticos de la II ${ }^{a}$ República y la Guerra de España han generado en los últimos treinta años un revisionismo histórico concienzudo. Sin embargo, son en muy menor medida los autores que han investigado sobre los colectivos de mujeres y su importancia en el devenir histórico reciente de nuestro país. A menudo los estudios sobre las mujeres activistas sociales y políticas en la España de la primera mitad del siglo XX, siguen constituyendo, "temas concretos de mujeres", y su inclusión en el corpus histórico sigue estando sujeta a criterios individuales, presentando en la mayor parte de ocasiones la participación de las mujeres como algo anecdótico, o como complemento "sociocultural" de la historia "viril", pero nunca en pie de igualdad. Buena muestra de ello son los actuales libros de texto de literatura y de historia del alumnado de Secundaria y de Bachillerato en España, donde la ausencia de las luchas y de los escritos de las mujeres de nuestra historia reciente es un hecho de fácil comprobación. Y, sin embargo, la historia de las mujeres que contribuyeron en España durante la primera mitad del siglo $\mathrm{XX}$ a procurar un estado democrático, social y justo constituye una fuente destacable de interés por sí misma.

Las notables "ausencias" que permanecen hoy en día en el corpus histórico son aún más injustificables en una sociedad moderna que se quiere paritaria, equitativa y justa. En efecto, si bien algunas figuras relevantes por sus cargos políticos o ministeriales como Dolores Ibárruri, Margarita Nelken o Federica Montseny son nombradas -de pasada, por supuesto-, las luchas de las mujeres anarquistas, de las sindicalistas, de las obreras o de las campesinas son completamente relegadas al olvido, no merecedoras del reconocimiento histórico o institucional. Fueron y siguen siendo ciudadanas de segundo orden. Es cierto que la investigación de estos colectivos es dificultosa, porque el franquismo ha procurado -y sigue procurando- la desaparición o el ocultamiento de archivos, necesarios para reestructurar con justicia una historia de España, aún por consensuar de una vez por todas. En las últimas décadas, gracias a investigadoras como Mary Nash, Susanna Tavera o Antonina Rodrigo, al menos se habrán inmortalizado mujeres de España comprometidas. Son valientes y apasionadas librepensadoras que desdibujan la teoría de la mujer domesticada, cuya única actividad durante la guerra de España habría sido el cuidado de heridos, el zurcido de prendas de hombre para el frente o como mucho el trabajo en la fábrica sustituyendo temporalmente al hombre, dotado de la misión de salvar España. Las mujeres no salvaron España, solamente la asistieron. Esta es la conclusión preliminar que se ofrece históricamente en relación a las actuaciones de las mujeres durante la contienda provocada por la rebelión franquista.

Por otra parte, es necesario remarcar la mala prensa que se le ha procurado y se le sigue procurando al movimiento anarquista español, ejemplo único en la historia mundial del anarquismo que desarrolló un proyecto sociocultural, económico y político compartido con ilusión y esperanza por millones de personas de la clase trabajadora. Fue un movimiento consolidado que procuró cambios estructurales y políticos modernos para España, al cual se procura ignorar en el mejor de los casos y desprestigiar la mayoría de las veces.

Teniendo en cuenta estos factores, ser mujer es objeto de poca o nula atención por parte de los historiadores, pero ser mujer y simpatizante anarquista, es aún en el siglo XXI percibido en España como sinónimo de peligro y subversión. Por ello es necesario que las mujeres -invitados quedan, por supuesto, los hombres- hagan todos los esfuerzos posibles para rescatar la historia de las luchas de nuestras antecesoras. La reivindicación de la verdad histórica con perspectiva de género debe de seguir existiendo con fuerza inquebrantable hasta que algún día logremos todos y todas reconocer y conocer una verdad histórica auténtica, plural y justa.

Por todo lo expuesto es más que evidente la necesidad de recuperar investigaciones fundamentales y divulgarlas. Por medio del estudio de una selección de escritos de la doctora Amparo Poch y Gascón publicados en España, se pretende restituir en su justo lugar a esta entregada activista adelantada a su tiempo, que dedicó su vida a dos de los colectivos más frágiles: el de las mujeres y el de los niños y las niñas. Se le debe un especial reconocimiento a su aportación a la mejora educativa, terapéutica y social del país.

Amparo Poch y Gascón (1902-1968) nació en Zaragoza en un contexto de agitación social y de despertar del sindicalismo revolucionario. Criada en un hogar modesto, desde niña sorprendió por su capacidad de observación, su sensibilización a los problemas sociales y su brillantez académica. Decidida desde niña a cursar la carrera de medicina, se ve sometida a la autoridad patriarcal que solo la permite realizar estudios únicamente "femeninos". Así que ingresa en 1917 en la Escuela Normal Superior de Maestros de Zaragoza, terminando sus estudios en 1922 con premio extraordinario en la sección de ciencias. Sin embargo, a sus 20 años, Amparo Poch es ya una mujer intrépida que se rebela contra la opresión sexista de la época y que frecuenta desde 1918 círculos revolucionarios en su Zaragoza natal que fundamentarán su anarquismo y el rechazo a todo tipo de explotación humana.

Aún en contra de su padre, esta pionera científica se matriculará en la Facultad de Medicina de Zaragoza en 1923, siendo entonces la única alumna de su curso, de los 435 matriculados (Rodrigo, 2002b). Toda su carrera la desarrollará bajo la dictadura de Primo de Rivera, alternando sus estudios con publicaciones en periódicos radicales como "La voz de la Región" o "La voz de Aragón". Desde sus primeros escritos Amparo Poch manifiesta su preocupación por la regeneración social y política y por la emancipación de la mujer. Su paso por la Facultad de Medicina no pasó desapercibido 
para nadie, como alumna brillante y como luchadora feminista. Prueba de ello es la controversia originada en 1923 a raíz de un artículo de la "Revista del Ateneo Científico Escolar" titulado "¿Qué seré yo?" escrito por la estudiante Emilia Félez, que expone su desconfianza hacia las mujeres que estudian medicina para ejercerla, recordando que el papel de la mujer es el de esposa y madre. La respuesta de Amparo Poch no se hace esperar y en el siguiente número de la revista en el artículo "¿Y yo?" expresa con ironía su rechazo a la supuesta incapacidad de la mujer para ejercer la medicina a la par que justifica sus argumentos haciendo un acertado repaso de grandes profesionales femeninas, mostrando un gran conocimiento acerca de mujeres pioneras del mundo y su negación a aceptar convencionalismos arcaicos:

Yo no sé cómo resolvería el caso la gran Concepción Arenal, que desempeñó cargos oficiales, [...] Yo no sé cómo habrán resuelto el caso Concha Espina, Sofía Casanova, la señorita Dautschakoff, la primera mujer que desempeñó una cátedra oficial en el Imperio Ruso, perteneciendo al Claustro del Instituto Histológico de la Universidad de Moscou; Henry Peterson, la primera mujer abogada que informó en Dinamarca; las cirujanas y médicas que en el siglo XII hubo en Bolonia y Palermo, y en nuestros días se encuentran en Rusia, Alemania, Suecia y particularmente los Estados Unidos, donde hay más de cuatro mil médicas, algunas de lanente en los Estados Unich de las cuales en Inglaterra de trescientas... (Poch, 1923, in Rodrigo, 2002b: 78-79)

Su lucha por el reconocimiento de la mujer de cualquier clase social y de la paridad entre sexos serán objeto de una acción perseverante a lo largo de su vida. Librepensadora y escritora reivindicativa, desde muy joven se expresará con crítica contundencia, como en el texto "Sobre feminismo. Más ideas acerca de las mujeres", publicado en "La voz de Aragón": “La mujer quiere ser atendida, no tolerada; quiere ser igual, no inferior. [...] Uno al lado del otro, poder a poder, por el camino de la misma Justicia y de la misma Moral" (Poch, 1928, in Rodrigo, 2002a: 83-84).

Escritora versátil, publica en 1923 a sus 21 años, su primera y única novela Amor. Es sin duda una novela de juventud, bien construida y de amena lectura que podría encuadrarse dentro de la novela rosa anarquista según las características propuestas por Antonio Prado (2011) en su estudio sobre escritoras anarco-feministas, tanto en aspectos formales -lenguaje cuidado- como en el uso de temas -amorosos y sociopolíticos- o la caracterización de la protagonista -heroína liberada y emancipada. Para este autor la novela rosa anarquista utiliza un código léxico subversivo que la diferenciaría de la típica novela rosa, conservadora y poco formativa para la mujer. En la novela de Amparo Poch encontraremos términos propios del contexto revolucionario: regeneración humana, hipocresía burguesa, revolución socialista, liberación de la mujer... en oposición al registro autoritario patriarcal, pero siempre en tono delicado, con lenguaje amoroso, buscando captar la atención sobre todo de las lectoras y de paso formarlas en los valores anarquistas. Amor es una novela basada en el propio entorno y en las propias experiencias personales de Amparo Poch como activista revolucionaria dejando traslucir su determinado feminismo, sus convicciones libertarias y su antibelicismo, valores consolidados desde bien joven, temas recurrentes en sus posteriores escritos. Las relaciones entre Amor Solís y Julio Montes, los protagonistas de la novela, vehiculan una crítica feroz del hombre sexista que no ve con buenos ojos a la mujer moderna y al cual le cuesta realmente hacer un esfuerzo de deconstrucción para superar una educación férreamente misógina.

La protagonista es el ejemplo de la mujer moderna y emancipada, que se decanta por el amor libre. El texto es además muy interesante porque constituye una descripción del agitado contexto social de la época: Amor Solís es asesinada en un fuego cruzado callejero de pistoleros. La autora establece una consecuencia lógica del uso de las armas y se pueden rastrear en su novela críticas al anarquismo virulento. Amparo Poch se adhirió a la corriente treintista disidente de la CNT y al Partido Sindicalista fundado en 1933 por el anarcosindicalista Ángel Pestaña, uno de los dirigentes de la corriente reformista que se escindió de la CNT, desvinculándose de la perpetración de actos violentos y promulgando la revolución social por medio de la educación.

Al final de su carrera Amparo Poch realiza sus prácticas en el hospital: interesada por la especialización materno-infantil, queda fuertemente impactada por las imágenes de niños tarados y deformes a causa de la miseria y sobre todo por la transmisión de las enfermedades venéreas, lacra social de la época. En el artículo "La otra moral" su indignación se acrecienta ante la despiadada discriminación de niños y mujeres gravemente contagiados:

Por esos pobres niños y por esas mujeres, vengo yo a terminar con un recuerdo a la moral masculina, entre tantas voces que acusan a la mujer de frívola e impura entre tantos dedos que la señalan como contagiada de todas las degeneraciones. [...] de esa sociedad que las aparta a un lado y que las deja con sus hijos, a merced (0). 2002a: 70)

Consciente de la gran ignorancia del país, del poco uso de los medios profilácticos y de la gran afluencia de los hombres a los prostíbulos, inaugurará a partir de entonces un ciclo formativo de escritura: la divulgación de la ciencia y de la puericultura.

Amparo Poch se licenció con 27 años en Medicina y Cirugía en 1929 con Premio Extraordinario, siendo la segunda alumna interna que obtuvo el título en la Facultad de Medicina de Zaragoza. Se inscribió en el Colegio de Médicos, en el cual también desempeñó el cargo de Vicesecretaria desde 1929 hasta 1934. La doctora Poch abrirá en 1929 su primer consultorio para mujeres y niños en Zaragoza, con un horario 
de atención y precios especiales para obreras, a la par que prestará desde 1930 sus servicios en el Hospital Provincial de Zaragoza.

Para contribuir a la divulgación de la puericultura escribió el manual Cartilla de consejos a las madres (1931), destinado a informar a las mujeres sobre el periodo de gestación y la lactancia del niño. La divulgación pedagógica incluía la condena del aborto clandestino que tantas muertes ocasionaba. La doctora Poch era partidaria del aborto en determinados supuestos, que coinciden grosso modo con los aprobados por la ley española en 2010 sobre la interrupción voluntaria del embarazo. Como se puede comprobar, también en este terreno la doctora Poch fue una adelantada a su tiempo. La cartilla también incluía análisis y consejos de prevención de riesgos laborales relacionados con la intoxicación de metales ocasionada por el trabajo de las madres en las fábricas Sus consejos son sencillos, didácticos y vanguardistas si los contextualizamos en su época. Cartilla de consejos a las madres fue galardonada en el II Concurso de premios Dr. Borobio por actos de protección a la infancia.

En 1932 Amparo Poch publica un opúsculo revolucionario enmarcado dentro de la tradición libertaria en la colección Cuadernos de cultura, una publicación de gran difusión en medios estudiantiles y obreros: "La vida sexual de la mujer". El documento incluye la divulgación científica, pero también denuncias y críticas sociales. Una de ellas constituye la denuncia de una educación de moral represora y antipedagógica fomentada por el catolicismo:

La gran mayoría de las escuelas no puede educar en el amor a la Pureza, a la Sencillez, a la Verdad, porque son producto de una moral toda de escondrijos y malicia; porque aún intentan, tenazmente, iniciar en la Ciencia bebiendo en las fuentes de una religión que ha martirizado bárbaramente a cuantos hombres sabios, nobles y liberales se atrevieron a descubrirla con la luz de su genio (Poch, 1932: 8).

Amparo Pochopina queni las maestrasestán capacitadas para impartir una educación sexual, ni tampoco las madres, condicionadas por una sociedad decimonónica que aún identifica la vagina con el pecado. Como medidas de higiene moral reclama la coeducación y la renovación formativa que incluya la adquisición de conocimientos anatómicos y fisiológicos, como primer paso para el autoconocimiento y la afirmación personal. Se lamenta de los pocos estudios existentes sobre la fase que ella estima fundamental en la vida de la mujer: la aparición de sus primeros impulsos sexuales. Denuncia la moral rígida que impone la abstinencia sexual a los novios antes del matrimonio, fomentando así las frecuentes visitas del novio a los prostíbulos. Sabe que sus propuestas chocan con la moral burguesa, pero igualmente advierte de la necesaria regeneración social para paliar los problemas ocasionados por una moral represora.
La clave de la modernización de la mujer está en su acceso a la educación, que debe de ayudarle a formarse, emanciparse y liberarse de la dependencia del hombre. Considera que la formación influirá beneficiosamente en las relaciones de pareja, por ello reclama para los jóvenes: "centros donde se enseñe, obligatoriamente, las ideas más fundamentales de la evolución y de la herencia, con la higiene sexual, a los que aspiren a unirse amorosamente" (Poch: 1932: 31). Amparo Poch es una importante divulgadora del neomalthusianismo en España, teoría muy difundida desde finales del siglo XIX en el ámbito del anarquismo social, que promulga el necesario control de la natalidad entre las clases obreras, la difusión de una sexualidad y reproducción libre de enfermedades venéreas, la divulgación de métodos anticonceptivos para una procreación consciente, la defensa de la maternidad libre y la formación en puericultura. La parte del volumen dedicada al matrimonio se abre con una aclaración explícita en relación a su subtítulo: "El matrimonio, si damos a esta palabra el sentido de unión amorosa monógama, desentendiéndonos de las ceremonias religiosas o judiciales que se le añaden, es una ciencia, según Balzac" (Poch, 1932: 32).

Denuncia el uso del lenguaje que vehicula un concepto de propiedad y servidumbre desigual entre los miembros de la pareja tanto entre los hombres -mi mujer- como entre las mujeres -señora de- y manifiesta duramente su crítica al colectivo masculino: “Los hombres españoles -salvo excepciones confirmadoras de la regla- no han llegado al grado de educación, a la madurez de inteligencia, a la superación moral necesarias para recibir y convivir con una mujer nueva" (Poch, 1932: 32). Si bien cita a Federica Montseny, referente frecuente en los escritos de la autora, en la descripción del modelo de la mujer nueva, se advierte en el capítulo "Matrimonio" la fuerte influencia de la publicación Las relaciones sexuales y la lucha de clases (1911), de la carismática activista feminista y comunista Alejandra Kolontai, a partir de la cual desarrolla su discurso de emancipación sexual femenina. Tras la introducción sociológica y partiendo del postulado de que la unión sexual es necesaria para la perpetuación de la especie, Amparo Poch inicia un estudio de divulgación biológica del origen de la vida, tomando como referencia las teorías de importantes científicos evolucionistas, hasta llegar de forma gradual a la fisiología descriptiva de la mujer. Científica rigurosa, cada tema se complementa con datos estadísticos o sociológicos actualizados. La crítica social libertaria se inserta en el discurso de divulgación científica: "Pertenecen al capítulo de la higiene matrimonial la lucha contra la prostitución, contra el alcoholismo y contra todas las lacras sociales. También son de higiene matrimonial la supresión de la intromisión religiosa en la unión amorosa; así como la intervención de las legislaciones, plagadas de vejeces e impurezas" (Poch, 1932: 42). Las últimas líneas del divulgativo opúsculo revolucionario "La vida sexual de la mujer" sintetizan la esencia de la publicación: 
Cerraremos este CUADERNO invitando a cuantos se amen a considerar el elevado significado de la unión amorosa, su importancia social, su categoría biológica. Les invitamos sinceramente a considerarlo todo limpio de prejuicios morales, de mora arruinada; pensando que una moral nueva y poderosa ha de fundamentarse, sobre los pilares de nuestra naturaleza, de acuerdo con ella, y abiertamente en contra de la hasta ahora imperante, de fracasada burguesía y artificioso contenido (Poch, 1932: 44).

En 1934, a raíz de violentos acontecimientos relacionados con la Revolución de Octubre, la doctora Poch se traslada a Madrid, donde abrirá un consultorio médico -con especial horario de atención para las obreras- y también prestaría sus servicios en la Mutua de Médicos de la CNT. Siempre entregada a las cuestiones sociales y a la formación en la higiene sexual, seguirá impartiendo conferencias y cursos de formación en los ateneos libertarios o en los locales de la CNT. Según el escritor libertario Gregorio Gallego, se le debe a la doctora Poch la fórmula y difusión de un espermicida, algo insólito para la época, y revela el alto nivel de compromiso social de la doctora: "Era presidenta de la Sociedad de Refractarios a la Guerra; Fundadora del 'Grupo Ogino' y propagandista de este sistema anticonceptivo y profetisa de las teorías pacifistas de Norman Angell" (Rodrigo, 2002b: 78).

El pacifismo fue otro mensaje que Amparo Poch difundió denostadamente a lo largo de su vida. En 1935, en el artículo "Frente al gesto bélico" publicado en la revista "Tiempos Nuevos", la autora hacía un llamamiento a las mujeres ante el clima de guerra que se estaba fraguando en España. Sacude enérgicamente sus conciencias, reprobando su participación en la guerra, recordando que es un crimen contra la humanidad, por lo que formula a las mujeres un llamamiento claro y urgente a la insumisión:

Fuisteis a las fábricas de armas y explosivos, para empaquetar y pulir con vuestras manos la más odiosa de las muertes. La que iba zumbando, estallando, sobre las cabezas encogidas de los compañeros de otras mujeres...que también se afanaban porque también tenían un pedazo de esa múltiple razón de las guerras. [...] Hay que apresurarse; hay que apresurarse y acabar con todo eso. No levantéis la cabeza, mujeres, para mirar la tela simbólica; bajadla para mirar la evolución humana martirizada cruelmente por sus insensibles directores. No prestéis oídos a los himnos nacionales ni a las palabras retumbantes que os hablen de falsos deberes patrióticos. [...] Pasad con energía a defender la paz y la dulzura. Pasad sobre el gesto, sobre la institución, sobre la fuerza y el escándalo (Poch, 1935, in Rodrigo, 2002a: 85-86).

Para implementar su acción antibelicista en 1936 fundó y presidió junto a un grupo de pacifistas la Liga Hispánica contra la Guerra, sección española de la War Resisters' International, colectivo antimilitarista fundado en 1921 aún activo en la actualidad. En "La guerra sobre los niños" publicado en "El sindicalista", Amparo Poch redactaba firmemente su declaración de principios: “Nuestra conciencia rechaza de plano la guerra; nuestro corazón no puede admitir la violencia como razonable y justa en ninguna ocasión" (1937, en Rodrigo, 2002a: 42).

El año de 1936 marca el inicio de uno de los peores acontecimientos de la Historia de España, pero también es la fecha de un acontecimiento constructivo, bello y generoso, muy digno de ocupar un lugar de importancia en la historia reciente de nuestro país por su magnífica contribución al feminismo, a la democracia y a la mejora social: la constitución de la Agrupación Mujeres Libres. La igualdad entre los sexos era objeto de debate desde hacía años entre los círculos y sindicatos anarquistas, pero en la práctica no se lograba ninguna realización. Por ello, activistas comprometidas fundaron la Agrupación Mujeres Libres en abril de 1936. En principio el proyecto comenzó con la creación de la revista que lleva su mismo nombre, pero desembocó en una organización feminista fundamentada en principios libertarios. Tres fueron las fundadoras: Lucía Sánchez Saornil, Mercedes Comaposada y Amparo Poch y Gascón. Mary Nash, estudiosa de los movimientos feministas españoles, publicó una selección crítica de textos de la agrupación feminista y de su revista, "Mujeres Libres" España 1936-1939, proporcionando una excelente idea de conjunto del compromiso con la emancipación de las mujeres de las clases trabajadoras y de la ideología libertaria de la agrupación:

Mujeres Libres partía de una doble conciencia: en primer lugar, una conciencia social y política, que se identificaba con la clase obrera y, en segundo lugar, una conciencia feminista que le hacía reivindicar la liberación de la mujer de su estado de opresión como mujer. Esta característica de feminismo proletario es quizás el elemento más original de la organización (Nash, 1975: 23).

Si bien existían otros colectivos feministas. como la Unión del Feminismo Español o el Lyceum Club, todos ellos se habían constituido en clases sociales acomodadas y sus actuaciones no calaron en el conjunto mayoritario social de mujeres. Las finalidades concretas de la Agrupación Mujeres Libres eran: "Emancipar a la mujer de la triple esclavitud a que, generalmente, ha estado y sigue estando sometida: esclavitud de ignorancia, esclavitud de mujer y esclavitud de productora" (1936, in Nash, 1975: 73). Mujeres Libres trabajará en la misma línea de otra luchadora anarcofeminista adelantada a su tiempo, Teresa Claramunt, que expuso la teoría de la necesaria liberación de las mujeres para la consecución de igualdad de derechos laborales en la publicación La mujer, consideración sobre su estado ante las prerrogativas del hombre (1905). El éxito de la agrupación anarcofeminista Mujeres Libres fue arrollador, contando en menos de tres años con 28.000 adheridas o simpatizantes (CGT, 2012: 28), aglutinando cerca de 147 agrupaciones de mujeres hasta constituirse como Federación Nacional Mujeres Libres. Las fundadoras y colaboradoras de la agrupación idearon grandes y 
hermosos proyectos sociales que no pudieron desarrollarse en su totalidad a causa del golpe de estado franquista.

La revista "Mujeres Libres", subtitulada Cultura y Documentación social, tenía grandes aspiraciones: captar a mujeres para el movimiento libertario, aumentar la formación intelectual de sus lectoras y ofrecer escritos de fácil divulgación entre las clases populares poco instruidas. Son destacables las contribuciones de la escritora Carmen Conde, o las de la pedagoga y traductora Etta Federn, de la líder sindical Federica Montseny, de la pedagoga racionalista Pilar Grangel o de la de pionera libertaria y feminista Emma Goldman, que apoyó entusiasmada la formación. La revista ofrecía una gran variedad de artículos de opinión, culturales, artísticos o formativos, siempre abordados con un lenguaje cuidado y una sensibilidad exquisita, nunca exentos de crítica sociopolítica o feminista ni de mensajes libertarios y pacifistas.

Una de las primeras aportaciones de Amparo Poch a la revista "Mujeres Libres" fue "Elogio del amor libre" un escrito redactado en prosa poética que finaliza con un envío, a la manera de la poesía trovadoresca. En el capítulo "Plegaria del Amor Libre" la autora explicita su rechazo a las uniones conservadoras, exentas de amor:

Yo no tengo Casa. Tengo, sí, un techo amable para resguardarte de la lluvia y un lecho para que descanses y me hables de amor. Pero no tengo Casa. ¡No quiero! No quiero la insaciable ventosa que ahíla el Pensamiento, absorbe la Voluntad, mata e Ensueño, rompe la dulce línea de la Paz y el Amor. Yo no tengo Casa. Quiero amar en el anchuroso más "allá" que no cierra ningún muro ni limita ningún egoísmo.

(Poch, 1936, in Rodrigo 2002a: 95)

En coherencia con su ideología implementa el discurso poético con el social recordando a las mujeres la obligación de su emancipación para mejor disfrute de los amantes, por ello le recomienda cultivar su inteligencia y proyectar su sensibilidad: " $\mathrm{Si}$ no te capacitas, mujer, serás un ser de instintos, serás una carne monótona y limitada, cerrada en ti misma y por ti abolida." (Poch, 1936, in Rodrigo, 2002a: 96). El capítulo "Matrimonio y amor" es específicamente libertario y especialmente virulento contra el sometimiento institucional y religioso que domina las uniones entre las parejas y la consideración de la mujer como esclava o mercancía, por ello denuncia que: “Del gesto amoroso se hizo un minucioso código, muerto y frío; del más grato y ardiente regalo, una compraventa en veces, con su reglamento y todo" (Poch, 1936, en Rodrigo, 2002a: 97). También denuncia la utilización de los hijos como chantaje moral convirtiendo la unión en indisoluble. La autora recuerda que durante siglos la mujer ha estado sumida en una tremenda ignorancia siendo excluida de las tareas de producción o de los trabajos públicos, no representando más que una esclava sexual doméstica. En el capítulo “Amor Libre!” categoriza los tres modelos de mujer a abolir y difunde el modelo de la mujer nueva, libre de ataduras que decide por sí misma entregarse al amante sin condicionamientos ni sometimiento alguno:

¡La Vida está harta ya de la Mujer-esposa, pesada, demasiado eterna, [...] está harta de la Mujer-prostituta, a la que ya no queda sino la raíz escuetamente animal, está harta de la Mujer-virtud, seria, blanca, insípida, muda...[...] Crea el nuevo tipo; pon la sal en la Vida; el color y la llama en los besos desiguales. Ama, habla, trabaja. Comprende, ayuda consuela Aprende a desaparecer y a descargar de tu presen. por sosiego iAmor Libre! (Poch, 1936, en Rodrigo, 2002a: 100).

Otra aportación originalísima de Amparo Poch a la revista de Mujeres Libres fue el conjunto de textos englobados bajo el título La Ciencia en la mochila. Sanatorio del Optimismo, firmados por la Doctora Salud Alegre. La risa y el buen humor constituían parte del carácter de la doctora Poch, que creía sinceramente en ellos como una terapia necesaria para afrontar las vicisitudes de la vida. Ya en 1923 había publicado el artículo "El buen humor" en el describía su magnífica condición terapéutica para el ser humano, invitando a cultivar la risa y el buen humor, augurando un sano porvenir espiritual: "Nos hace agradables, porque la alegría sana es comunicativa, espléndida. Nos atrae buenos amigos, porque los malvados huyen de la risa espontánea y sincera" (Poch, 1923, en Rodrigo, 2002a: 58-59). Los textos que conforman La ciencia en la mochila. Sanatorio del Optimismo no tratan en absoluto de divulgación científica, sino que constituyen una serie de artículos críticos sociopolíticos tratados de forma irónica o satírica, con un planteamiento estructural y léxico absolutamente surrealistas, algunos rayando en el absurdo. Los elementos futuristas, fantásticos u oníricos le confieren un valor añadido haciéndolos únicos.

Los personajes del Sanatorio del Optimismo incluyen a la propia Amparo Poch como Doctora Salud Alegre. Los doctores Buen Apetito, Sueño Feliz, Amor Humano y Guasa Viva, auxiliados por las enfermeras Ilusión, Fantasía y Risa, tratarán de actuar social e intelectualmente sobre sus enfermos para procurar su curación. Algunos de sus títulos son realmente chocantes, como "Proyección para la creación de una fábrica de bodas en serie (Churros auténticos)" en el que la autora ridiculiza cáusticamente la doble moral de algunos anarquistas que sentían la necesidad de un certificado que consignara una simple unión de hecho: "Cuando estaba el cura, os engañaba el cura; cuando estaba el juez, os engañaba el juez; ahora os engañamos nosotros, puesto que venís a eso" (Poch, 1936, in Rodrigo 2002a: 219). La crítica al feminismo burgués se expone en "Terrible fracaso". El equipo médico es llamado de urgencia a causa de la celebración de un mitin feminista: “¡Oh! Un mitin feminista es el espectáculo más lamentable que ustedes pueden imaginar. Tiene un pronunciado sabor de retroceso y estrechez de espíritu que da pena" (Poch, 1936, en Rodrigo 2002a: 212-213). La autora ridiculiza y denuncia las feministas que solo reivindican un lugar en la sociedad jerarquizada 
donde el hombre sigue manteniendo la superioridad. A cambio la autora propone un mundo sin guerras - desencadenadas por el hombre-, una desaparición del control estatal como, por ejemplo, la supresión de fiscales y notarios, y una sociedad donde la mujer y el hombre se unan libremente y conciban hijos cuando ellos los deseen. El folleto $\mathrm{n}^{\mathrm{o}} 4$ de la revista inicia una serie de artículos en los que se percibe un cambio de tono causado por la guerra, fundamentalmente escéptico. En “¡Oooooh! Ginebra”, el doctor Buen Humor está aquejado por un tumor que segrega una sustancia tóxica: la credulitas confiabilis. Diagnosticada la enfermedad, se propone un remedio heroico:

Una cura enérgica en Ginebra a base de S. de N., alcaloide cuyos efectosúltimamente descubiertos en España son todo lo contrario de lo que se creía hace cinco años, cuando los chicos nacían sin cabeza y había que ponérsela después a tornillo; y unas dosis audaces de Asambleas Internacionales acompañadas de masaje vibratorio en el mismísimo bulto (Poch, 1936, in CGT, 2012: 22)

A estos cuidados se añade una dieta a base de filetes de Comités controladores e intervencionistas, discursos en papeles mojados, píldoras de Primero de Mayo y un remedio infalible, un extracto de plantas adormideras: escepticismus. Con este último remedio, el doctor Buen Humor se cura definitivamente. Toda una crítica, feroz en contenido, divertida en metáforas y comparaciones, a la Sociedad de Naciones y a las Internacionales obreras comunistas y socialistas. El último texto de la serie "La raza esforzada del 'aval'” continúa la línea escéptica del texto anterior. El doctor Buen Humor desea adquirir unos calcetines rojos con ribetes morados, pero para ello debe detentar un aval sindical o político. Después de pasar por un sinfín de despachos, obtiene el aval y adquiere los calcetines republicanos. Pero véase en qué condiciones y como concluye el último de los textos de la serie de Amparo Poch y Gascón: “El comité puso en las manos del director del Sanatorio unas piltrafas de lana rojas. Eran los restos de los calcetines que se había comido la polilla. El doctor Buen Humor, jel pobre!, se plegó en tres dobleces y cayó al suelo desmayado" (1936, en CGT, 2012: 47).

Las colaboraciones de la revista "Mujeres Libres", también se publicaron en folletos, en otra edición del grupo: “Publicaciones Mujeres Libres”. Entre 1936 y 1938 se publicaron en Barcelona varios folletos entre los cuales Niño, un didáctico, tierno y, en ocasiones, poético manual de puericultura, escrito por la doctora Poch. Según Antonina Rodrigo (2002a) gozó de una gran difusión en la radio y una gran cantidad de ejemplares fue enviada a México por su embajador en España para ser difundido en las escuelas aztecas.

Desde los primeros días de la guerra la doctora Poch ofreció sus servicios como médica miliciana en los Hospitales de sangre de Madrid. Al mismo tiempo aparecía en la revista y en la calle la propaganda de otro proyecto humanitario y absolutamente revolucionario diseñado por la Agrupación Mujeres Libres: los Liberatorios de
Prostitución. Se ofrecía a las mujeres la oportunidad de abandonar la prostitución, ofreciéndole tratamiento médico fisiológico y psicológico, capacitación profesional y toda la ayuda moral y material necesaria para su integración social. La guerra mutiló el desarrollo de este magnífico proyecto, no dando tiempo más que a algunas realizaciones puntuales.

Defensora de la infancia, Amparo Poch publicó en 1936 en "Mujeres Libres" el texto "Niños, niños, niños" en el que se manifestaba en contra de la deliberada manipulación de los niños y de su politización: “Los niños no pueden ni deben ser católicos, ni socialistas, ni comunistas, ni libertarios. Los niños deben de ser solamente lo que son: niños" (Poch, 1936, in CGT: 18-19). Reclamaba respeto por la psicología infantil y el derecho a su integridad. Como presidenta de la War Resisters' International en España, Amparo Poch organizó la expedición de quinientos niños a México. A finales de agosto de 1936 fue nombrada por el Ministerio de Instrucción Pública miembro de la Junta de Protección de Huérfanos de Defensores de la República, colaborando con otras destacadas mujeres como María Zambrano en la protección de la infancia de las ciudades bombardeadas. En noviembre de 1936 el gobierno republicano se reorganiza y Federica Montseny, Ministra de Sanidad y Asistencia Social, nombra a la doctora Poch Consejera Nacional de Asistencia Social. Fue la responsable de las evacuaciones de niños dentro del territorio nacional, a Rusia y a Francia. Otro proyecto que desarrolló desde el Ministerio de Sanidad es la constitución de los Hogares Infantiles o la reforma de los orfanatos, tétricos lugares que albergaban niños en estado físico y psicológico deplorables.

En febrero de 1937 las Juventudes Libertarias organizaron un multitudinario mitin en Barcelona, con representación de jóvenes de todas las formaciones políticas. La única mujer invitada fue Amparo Poch en representación de Mujeres Libres. La gran oradora recordó que la mujer había sufrido la guerra por el ansia de poder de los hombres y que había sido lanzada a ella ignorante, luego indefensa. Por ello, la mujer debía de superarse, capacitarse para su emancipación y así ofrecer una colaboración eficiente. Analiza con mucha lucidez las consecuencias de la guerra para las mujeres en la publicación Tierra y Libertad:

Esta guerra espantosa que nos conmueve, esta guerra repugnante que nos avergïenza, haprecipitado los a para la mujer. [i.] A las muje para la mujer. [...] A las mujeres antifascistas y aún más a las que además de antifascistas son verdaderamente revolucionarias, la guerra les ha marcado un puesto, que, en la paz, hubieran conquistado difícilmente. [...] Así, los que para siempre quisieron ahogar las aspiraciones proletarias, han hecho de cada mujer un obrero más que defiende sus derechos; los que para siempre quisieron imponer su cruel dictadura, han hecho de cada mujer un ser rebelde. La catástrofe sangrienta que nos apena ha puesto sobre las mujeres el fardo pesado y honroso de todas las 
responsabilidades. Hay que levantarlo y triunfar. Sin competencias. Todos juntos (Poch, 1937, in Rodrigo, 2002b: 176).

Desde el otoño de 1937 la doctora Poch se ocupará en Barcelona de la dirección del Casal de la Dona Treballadora, un proyecto de Mujeres Libres para capacitar técnica y profesionalmente a la mujer obrera y ayudar a su emancipación facilitando su inserción laboral. El Casal tuvo un gran éxito llegando a tener más de 900 alumnas (CGT, 2012: 34). En una de sus visitas a España, en octubre de 1938, Emma Goldman visitó el Casal y se entrevistó con la doctora Poch, manifestándole su admiración por el proyecto emancipador que estaba dirigiendo.

La actividad en España de la doctora Poch se interrumpió brutalmente en febrero de 1939, exiliándose como cientos de miles de españoles, cruzando la frontera a pie. Amparo Poch y Gascón nunca regresó a España, falleciendo en Toulouse en 1968. $\mathrm{Su}$ vida en el exilio merece un capítulo aparte, digno de investigar específicamente. En el exilio no dejará de participar en la ayuda humanitaria ni de publicar artículos animando a la mujer y al hombre a construir un mundo mejor para todos y para todas. Multitud de sus escritos en el exilio permanecen aún diseminados y sería muy interesante completar este generoso perfil humano con el análisis de los mismos.

La enorme y positiva aportación de la libertaria doctora Amparo Poch y Gascón a la emancipación femenina, al sindicalismo, al pacifismo, a la educación, a la protección de la infancia y a la divulgación científica, desde luego merecen un reconocimiento y un justo lugar en la historia reciente de España.

\section{REFERENCIAS BIBLIOGRÁFICAS}

CGT, Confederación General del Trabajo (Ed.). Mujeres Libres. Antología 2012, Madrid, 2012. Nash, M., Mujeres Libres: España 1936-1939, Barcelona, Tusquets, 1975.

Poch y Gascón, A., “La vida sexual de la mujer”, Cuadernos de cultura, LVI (1932), pp. 1-44.

Prado, A., "Matrimonio, familia y estado: escritoras anarco-feministas", Revista Blanca (18981936), Madrid, Fundación de Estudios Libertarios Anselmo Lorenzo, 2011.

Rodrigo, A., Poch y Gascón, A., Textos de una médica libertaria. Zaragoza, Diputación de Zaragoza y Alcaraván ediciones, 2002a.

Rodrigo, A., Poch y Gascón, A., Una mujer libre. Amparo Poch y Gascón, médica y anarquista, Barcelona, Flor del viento, 2002b. 